\title{
$\beta$-cell adaptation in a mouse model of glucocorticoid-induced metabolic syndrome
}

\author{
Liselotte Fransson ${ }^{1}$, Stephanie Franzén ${ }^{2,3}$, Victoria Rosengren ${ }^{1}$, Petra Wolbert', \\ Åke Sjöholm ${ }^{1,4}$ and Henrik Ortsäter ${ }^{1}$ \\ ${ }^{1}$ Department of Clinical Science and Education, Södersjukhuset, Karolinska Institutet, SE-118 83 Stockholm, Sweden \\ ${ }^{2}$ Division of Drug Research, Experimental Renal Medicine, Department of Medical and Health Sciences and \\ ${ }^{3}$ Center of Medical Image Science and Visualization, Linköping University, SE-581 83 Linköping, Sweden \\ ${ }^{4}$ Department of Biochemistry and Molecular Biology, College of Medicine, University of South Alabama, Mobile, \\ Alabama 36688, USA
}

Correspondence should be addressed to H Ortsäter

Email

henrik.ortsater@ki.se

\begin{abstract}
Glucocorticoids (GCs) are stress hormones primarily responsible for mobilizing glucose to the circulation. Due to this effect, insulin resistance and glucose intolerance are concerns in patients with endogenous overproduction of GCs and in patients prescribed GC-based therapy. In addition, hypercortisolemic conditions share many characteristics with the metabolic syndrome. This study reports on a thorough characterization, in terms of glucose control and lipid handling, of a mouse model where corticosterone is given via the drinking water. C57BL/6J mice were treated with corticosterone (100 or $25 \mu \mathrm{g} / \mathrm{ml}$ ) or vehicle in their drinking water for 5 weeks after which they were subjected to insulin or glucose tolerance tests. GC-treated mice displayed increased food intake, body weight gain, and central fat deposit accumulations. In addition, the GC treatment led to dyslipidemia as well as accumulation of ectopic fat in the liver and skeletal muscle, having a substantial negative effect on insulin sensitivity. Also glucose intolerance and hypertension, both part of the metabolic syndrome, were evident in the GC-treated mice. However, the observed effects of corticosterone were reversed after drug removal. Furthermore, this study reveals insights into $\beta$-cell adaptation to the GC-induced insulin resistance. Increased pancreatic islet volume due to cell proliferation, increased insulin secretion capacity, and increased islet chaperone expression were found in GC-treated animals. This model mimics the human metabolic syndrome. It could be a valuable model for studying the complex mechanisms behind the development of the metabolic syndrome and type 2 diabetes, as well as the multifaceted relations between GC excess and disease.
\end{abstract}

Key Words
Journal of Endocrinology (2013) 219, 231-241

\section{Introduction}

Glucocorticoid (GC) hormones, like cortisol, are produced and released from the zona fasciculata of the adrenal gland under the control of a prototypic neuroendocrine feedback system of the hypothalamic-pituitary-adrenal (HPA) axis. GCs are stress hormones and secreted in response to a
- glucocorticoid

- diabetes

- insulin secretion

- obesity

- islet cells 
and ACTH release; hence, the steroid regulates its own release in a negative feedback loop. The CNS is thus the commander-in-chief of GC responses, providing an excellent example of close integration between the nervous and endocrine systems (Vegiopoulos \& Herzig 2007). GC steroid hormones exert their function in different target tissues by binding to intracellular receptors, either the GC receptor (GR) or the mineralocorticoid receptor (MR).

The GCs are a class of catabolic hormones that are primarily responsible for modulating carbohydrate metabolism (Wajchenberg et al. 1984). In principle, GCs mobilize glucose to the systemic circulation. In the liver, cortisol induces gluconeogenesis and potentiates the action of other hyperglycemic hormones (e.g. glucagon, catecholamines, and growth hormone) on glycogenolysis, which culminates in the release of glucose from the hepatocytes. Cortisol inhibits uptake and utilization of glucose in the skeletal muscle and adipose tissue by interfering with insulin signaling. The hormone also promotes muscle wasting via reduction of protein synthesis and via degradation of protein and release of amino acids. The effect of cortisol on glycemia is further enhanced through the increased breakdown of triglycerides in the adipose tissue, which provides energy and substrates for gluconeogenesis. The increased rate of protein metabolism leads to increased urinary nitrogen excretion and the induction of urea cycle enzymes (Gelfand et al. 1984, Quan \& Walser 1992).

Given these effects, insulin resistance and glucose intolerance are concerns both in patients with Cushing's syndrome and disease (endogenous overproduction of GCs) and in patients prescribed GC-based therapy for immunomodulatory purposes (Raul Ariza-Andraca et al. 1998, Gulliford et al. 2006). In addition, hypercortisolemic conditions share many characteristics with the metabolic syndrome (Anagnostis et al. 2009): a cluster of abnormalities including hyperglycemia, abdominal obesity, dyslipidemia, and hypertension (Kassi et al. 2011, Nikolopoulou \& Kadoglou 2012, Mendizabal et al. 2013). In line with the observed similarities between phenotypes associated with the metabolic syndrome and the pathologies associated with GC excess, patients with the metabolic syndrome display elevated levels of cortisol (Duclos et al. 2005, Misra et al. 2008, Sen et al. 2008, Weigensberg et al. 2008) as do patients with glucose intolerance (Reynolds et al. 2001). However, it should be noted that GC elevations in these conditions are far from as apparent as those seen in Cushing's patients. In addition, dysregulation of the HPA axis has been noted in patients with the metabolic syndrome (Anagnostis et al. 2009). Individuals with central obesity have been reported to have increased urinary free cortisol (Marin et al. 1992), loss of diurnal cortisol variation (Rosmond et al. 1998), and abnormal HPA suppression in response to higher doses of dexamethasone (Pasquali et al. 2002). Considering the phenotypical similarities between GC excess and the metabolic syndrome, there has been a hypothesis formulated that cortisol plays a role also in the metabolic syndrome (Vogelzangs et al. 2007, Anagnostis et al. 2009, Muhtz et al. 2009, Karatsoreos et al. 2010).

To study the mechanisms behind the adverse effects of long-term treatment with GCs, both rat and mouse models have been used. Implantation of corticosterone pellets subcutaneously into Sprague-Dawley rats in combination with a high-fat diet gave rise to glucose intolerance and elevated triglyceride levels in serum, thus mimicking some aspects of the metabolic syndrome (Shpilberg et al. 2012). However this model was not associated with obesity but rather a decrease in body weight, both when GCs were combined with high-fat diet and when given alone. The same phenomena are observed in Wistar rats treated via i.p. injections of dexamethasone for 5 consecutive days (Rafacho et al. 2008, 2010b, 2011). These findings might reflect GC-induced muscle wasting and stress. It has, however, been shown that repeated exposure to corticosterone does not alter muscle strength in rats (Barel et al. 2010). In this context, the reduction in body weight in rats receiving GCs does not completely mimic the phenotype of the metabolic syndrome seen in patients. In contrast to rats, mice exposed to chronic stress develop hypercortisolemia and obesity (Patterson et al. 2013). A potential mouse model for the metabolic syndrome was recently presented by Karatsoreos et al. (2010), in which mice were given corticosterone dissolved in their drinking water. This model has the benefit of reducing stress from animal handling and injections. Here, we report on a thorough characterization of this model in terms of glucose control and lipid handling. We also provide data on the adaptive response to insulin resistance that occurs in the pancreatic islets.

\section{Materials and methods}

\section{Animals and treatment}

Experiments were performed on 10-week-old male C57BL/6J mice (Nova, Sollentuna, Sweden) which were allowed to feed ad libitum and housed in $12 \mathrm{~h}$ light: $12 \mathrm{~h}$ darkness cycles. Animals were treated with corticosterone

Published by Bioscientifica Ltd 
(100 or $25 \mu \mathrm{g} / \mathrm{ml})$ or vehicle ( $1 \%$ ethanol) in their drinking water for 5 consecutive weeks after which they were subjected to insulin or glucose tolerance tests (intraperitoneal insulin tolerance test (IPinsTT) and intraperitoneal glucose tolerance test (IPGTT) respectively) and then killed by exposure to $\mathrm{CO}_{2}$. A subgroup of mice was also followed up in a recovery study, where, after the 5 weeks of treatment, the GCs were discontinued and all mice received vehicle for an additional 3 weeks, giving a total study period of 8 weeks. The study was performed according to the guidelines of the Karolinska Institutet and approved by the local animal ethics committee. Food intake, body weight, and fed and fasting blood glucose were monitored weekly, using a hand-held glucometer (One-Touch Ultra 2; LifeScan, Milpitas, CA, USA), and fasting serum was collected for evaluation of insulin levels with ELISA (Mercodia, Uppsala, Sweden). The last week of treatment, mice received i.p. injections of $50 \mathrm{mg} / \mathrm{kg}$ body weight BrdU for 7 days. A group of mice was also subjected to blood pressure measurements. After the 5 weeks of treatment, mice were killed and organs were collected. Pancreatic glands were dissected and either used immediately for islet isolation, for evaluation of total insulin content, or fixed in $4 \%$ phosphate-buffered paraformaldehyde, paraffin-embedded, and sectioned for immunohistochemistry. Fat deposits were weighed and liver and $M$. femoralis were snap-frozen for later sectioning and oil red $\mathrm{O}$ staining. Blood was collected for analysis of serum nonesterified fatty acids, cholesterol, and triglycerides (analyzed at Karolinska University Laboratory at Södersjukhuset, Stockholm and Center for Inherited Metabolic Diseases, Karolinska University Hospital, Solna) and C-peptide levels were evaluated using ELISA (Alpco Diagnostics, Salem, NH, USA).

\section{IPinsTT and IPGTT}

IPinsTT and IPGTT were performed during the fourth or fifth week of treatment and IPinsTT was also performed during the eighth week for the mice in the recovery sub study. For IPinsTT and IPGTT, mice were fasted 1 or $6 \mathrm{~h}$, respectively, and received i.p. injections of insulin $(1 \mathrm{U} / \mathrm{kg}$ body weight) or glucose ( $2 \mathrm{~g} / \mathrm{kg}$ body weight). Blood glucose was monitored at multiple times 0 to 60 (IPinsTT) or 120 (IPGTT) min after injection. In a short version of IPinsTT, mice received insulin or PBS by injection and were killed after $15 \mathrm{~min}$. Organs were snap-frozen and later subjected to western blot analysis for assessing the levels of phosphorylated AKT1/2/3.

\section{Oil red $O$ staining}

Frozen pieces of liver and M. femoralis were embedded in NEG-50 (Thermo Scientific, Waltham, MA, USA). Cryosections $(12 \mu \mathrm{m})$ were obtained from different parts of the tissues and stained for neutral lipids using oil red O (ORO), as previously described (Hagberg et al. 2010).

\section{Mean arterial pressure measurements}

Mice were sedated (2\% Isoflurane, Apoteket, Uppsala, Sweden) after 4 weeks of GC or vehicle treatment and catheters were surgically placed in the jugular vein for constant saline infusion $(10 \mathrm{ml} / \mathrm{h}$ per $\mathrm{kg})$ and in the carotid artery for measuring mean arterial pressure (PowerLab, ADInstruments, Spechbach, Germany). Mean arterial pressure was sampled during a $30 \mathrm{~min}$ period after surgery and the resting period.

\section{Immunohistochemistry}

Paraffin-embedded pancreatic glands were sectioned, stained for insulin (polyclonal guinea pig anti-insulin; DakoCytomation, Glostrup, Denmark) or BrdU (monoclonal rat anti-BrdU; Accurat Chemicals and Scientific Corporation, Westbury, NY, USA), and analyzed as previously described (Grankvist et al. 2012). For each pancreatic gland, the islet volume and BrdU incorporation were determined from all islets identified in nine sections from different parts of the gland. Islet volumes were estimated with the nucleofector method (Bock et al. 2003) using a computerized setup for stereology (newCAST Software, Visiopharm, Hoersholm, Denmark) and presented as mean islet volume. For BrdU incorporation (as a measure of DNA synthesis), BrdU-positive cells were counted and presented as number of BrdU-positive cells divided by islet volume.

\section{Total insulin content}

Splenic parts of pancreatic glands were obtained and wet weighed after killing the animal. Acid ethanol $(0.18 \mathrm{M} \mathrm{HCl}$ in 95\% ethanol) was added, pancreatic glands were homogenized by sonication and insulin was extracted over night at $4{ }^{\circ} \mathrm{C}$. Samples were clarified by centrifugation and used for insulin content evaluation using insulin ELISA (Mercodia).

\section{Islet isolation and glucose-stimulated insulin secretion}

Pancreatic glands were excised and islets were isolated by collagenase digestion. Islets used for chaperone expression

Published by Bioscientifica Ltd. 
were lysed directly after isolation and subjected to western blot or RT for cDNA synthesis and then RT-qPCR. Islets to be used for glucose-stimulated insulin secretion (GSIS) were allowed to recover overnight in culture medium as previously described (Grankvist et al. 2012). Islets were then subjected to GSIS with $30 \mathrm{~min}$ preincubation in calcium 5 (Ca5) buffer (containing $25 \mathrm{mM}$ HEPES, $125 \mathrm{mM}$ $\mathrm{NaCl}, 5.9 \mathrm{mM} \mathrm{KCl}, 1.2 \mathrm{mM} \mathrm{MgCl} 2,1.26 \mathrm{mM} \mathrm{CaCl}_{2}$, and $0.1 \%$ BSA) with $2 \mathrm{mM}$ glucose at $37^{\circ} \mathrm{C}$ followed by $60 \mathrm{~min}$ incubation in Ca5 buffer with either 2 or $20 \mathrm{mM}$ glucose at $37^{\circ} \mathrm{C}$. Buffers were collected for insulin analysis with ELISA (Mercodia). Islets were then washed with PBS, sonicated, and lysed and DNA was purified, and proteins were removed with phenol-chloroform extraction. DNA concentrations were measured by spectrophotometry (Picodrop Microliter u.v./Vis Spectrophotometer; Picodrop Ltd., Hinxton, UK) and GSIS data were normalized to islet DNA content.

\section{Protein extraction, SDS-PAGE, and western blot analysis}

Protein samples from isolated islets or other tissues were prepared for western blot analysis as previously described (Sargsyan et al. 2008). Protein concentrations were determined as described by Lowry et al. (1951). Immunoblot analyses were performed using rabbit primary antibodies against CANX, P4HB, HSPA5 (Abcam, Cambridge, UK), CALR, HSP90B1, PDIA4, the phosphorylated and total forms of EIF2K3 and EIF2A (Cell Signaling, Danvers, MA, USA), DDIT3, and the phosphorylated and total forms of AKT1/2/3 (Santa Cruz Biotechnology). Immunoreactive bands were detected using enhanced chemiluminescence (GE Healthcare, Fairfield, CT, USA), imaged, and quantified using Molecular Imager ChemiDoc XRS with Quantity One Software v. 4.6.5 (Bio-Rad Laboratories). After imaging, the polyvinylidene difluoride membranes were stained with Coomassie Brilliant Blue (Bio-Rad Laboratories) for total protein normalization.

\section{Islet total RNA extraction, reverse transcription for CDNA synthesis, and quantitative RT-PCR}

Total RNA was extracted from isolated islets using an Aurum Total RNA Mini kit and reverse transcribed into cDNA with iScript cDNA Synthesis kit (Bio-Rad Laboratories). The gene expression levels of mRNAs were measured by SYBR Greenbased quantitative real-time RT-PCR (Thermo Scientific) using mouse-specific primers for Calr, Canx, P4hb, Pdia4, $H s p 90 b 1$, and Hspa5. Actb was used as a housekeeping gene for normalization. The following formula was used for quantification: target amount $=2^{-\Delta \Delta C t}$, where $\Delta \Delta C t=$
$\left(C t_{\text {target gene }}-C \mathrm{t}_{\mathrm{Actb}}\right)_{\text {Sample }}-\left(C \mathrm{t}_{\text {target gene }}-C \mathrm{t}_{\mathrm{Actb}}\right)_{\text {Control }}$ (Livak \& Schmittgen 2001). For detailed information about the primers, see Supplementary Table S1, see section on supplementary data given at the end of this article.

\section{Statistical analysis}

Data are presented as mean \pm s.E.M. Student's $t$-test, or one-way ANOVA followed by Bonferroni post-hoc test, was used as appropriate to identify differences between groups, using GraphPad Prism 5.0 Software (GraphPad, La Jolla, CA, USA). A value of $P<0.05$ was considered statistically significant.

\section{Results}

Corticosterone exposure induces obesity, dyslipidemia, ectopic steatosis, and hypertension

Mice receiving corticosterone via their drinking water developed enlarged fat deposits (Fig. 1A and Supplementary Figure 1, see section on supplementary data given at the end of this article). The higher dose $(100 \mu \mathrm{g} / \mathrm{ml})$ led to a net body weight gain (Fig. 1B), which was associated with a higher food intake (Supplementary Figure 2). In a pattern consistent with obesity, mice treated with corticosterone displayed dyslipidemia as indicated by elevated serum levels of nonesterified fatty acids, cholesterol, and triglycerides (Fig. 1C). Also ectopic fat deposition was evident in the model; mice receiving $100 \mu \mathrm{g} / \mathrm{ml}$ corticosterone via their drinking water showed a significant increase in neutral lipid staining in cryosections of liver and skeletal muscle (M. femoralis) compared with vehicletreated animals (Fig. 1D). Obesity and dyslipidemia are part of the metabolic syndrome and so is hypertension (Kassi et al. 2011). We therefore investigated mean arterial blood pressure after 4 weeks of GC treatment. Mice treated with $100 \mu \mathrm{g} / \mathrm{ml}$ corticosterone had increased mean arterial pressure compared with vehicle-treated animals (Fig. 1E). In conclusion, administration of corticosterone to mice via the drinking water leads to obesity, dyslipidemia, ectopic fat deposition in the liver and skeletal muscle as well as hypertension, thus well mimicking the phenotype seen in patients with the metabolic syndrome.

\section{Corticosterone exposure induces glucose intolerance and insulin resistance}

To investigate glucose control in the mice treated with corticosterone, serum insulin and blood glucose levels

Published by Bioscientifica Ltd 
A

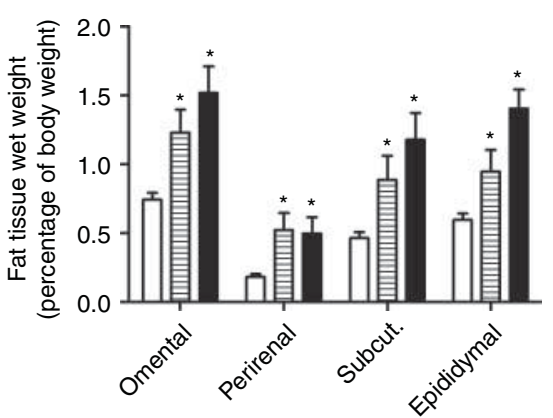

C
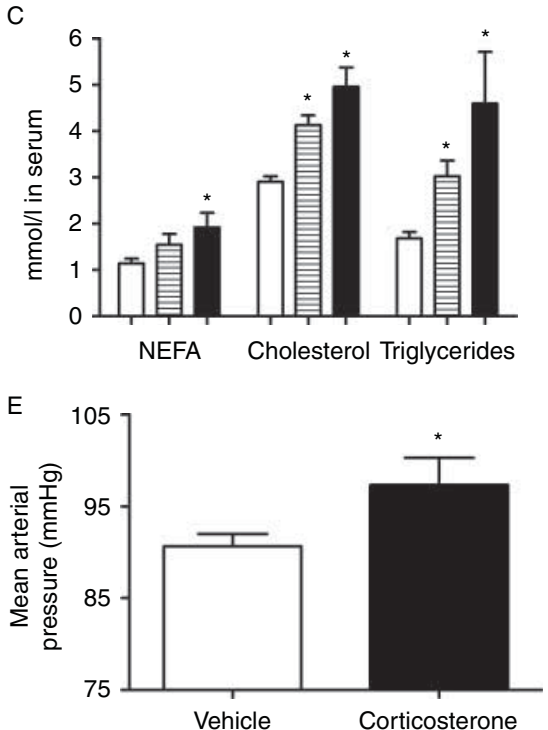

B

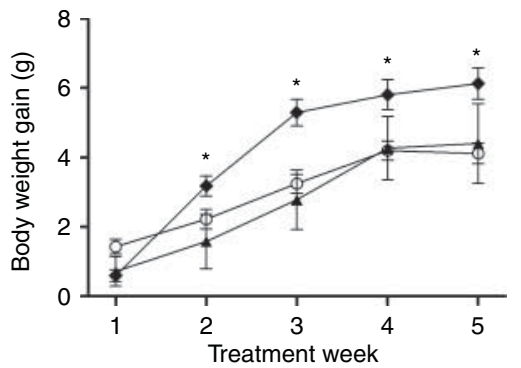

D
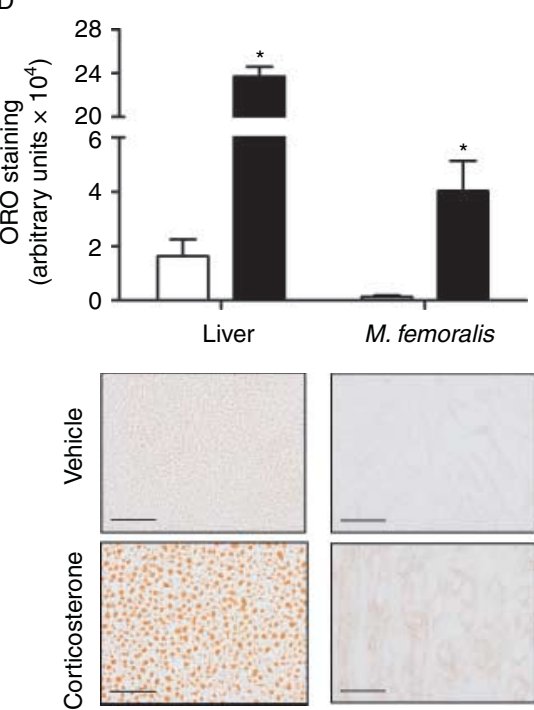

Figure 1

Corticosterone induces obesity, dyslipidemia, ectopic steatosis, and hypertension in mice. Fat deposits (A) and serum non-esterified fatty acids (NEFA), cholesterol, and triglycerides (C) are shown after 5 weeks of treatment with vehicle (white bars), $25 \mu \mathrm{g} / \mathrm{ml}$ corticosterone (striped bars) or $100 \mu \mathrm{g} / \mathrm{ml}$ corticosterone (black bars) via the drinking water. $(n=5-15)$. Body weight gain during treatment in mice receiving vehicle (white circles), $25 \mu \mathrm{g} / \mathrm{ml}$ corticosterone (black triangles) or $100 \mu \mathrm{g} / \mathrm{ml}$ corticosterone (black

were measured every week in fasted or random-fed mice throughout the study period. Corticosterone given via the drinking water dose- and time-dependently increased fasting serum insulin levels (Fig. 2A) compared with vehicle-treated animals. In addition, serum C-peptide levels measured at the end of the treatment period were increased in mice receiving both 25 and $100 \mu \mathrm{g} / \mathrm{ml}$ (Supplementary Figure 3, see section on supplementary data given at the end of this article). At the dose of $25 \mu \mathrm{g} / \mathrm{ml}$, mice maintained euglycemia over the 5-week exposure period, while those mice that received the higher dose $(100 \mu \mathrm{g} / \mathrm{ml})$ lost glucose control and displayed postprandial hyperglycemia (Fig. 2B). In contrast to the elevated glucose levels seen in random-fed mice, fasting diamonds) ( $n=6-37)$ is shown in B. Ectopic fat in liver and M. femoralis (D) and mean arterial pressure $(E)$ are shown after 5 weeks treatment with vehicle (white bars) or $100 \mu \mathrm{g} / \mathrm{ml}$ corticosterone (black bars) $(n=3-6)$. Images in (D) are representative pictures of ORO staining in the examined tissues (20× magnification, bars represent $150 \mu \mathrm{m})$. Data are shown as mean \pm s.E.M. $A$ * denotes a statistically significant $(P<0.05)$ effect of corticosterone treatment.

blood glucose levels were not increased in corticosteronetreated mice, irrespective of the dose (data not shown). To further characterize glucose tolerance in corticosteronetreated mice, an IPinsTT and an IPGTT were performed after 4 and 5 weeks of corticosterone treatment respectively. Insulin only modestly decreased glycemia in mice treated with corticosterone, indicating insulin resistance (Fig. 2C). Insulin resistance was further evident from analysis of insulin-induced phosphorylation of AKT1/2/3 in the heart, liver and skeletal muscle tissues; while insulin caused a twofold to threefold induction of phosphorylated AKT1/2/3 in vehicle-treated animals, the hormone failed to induce AKT1/2/3 phosphorylation in corticosteronetreated mice (Fig. 2E and F), further demonstrating insulin 
A

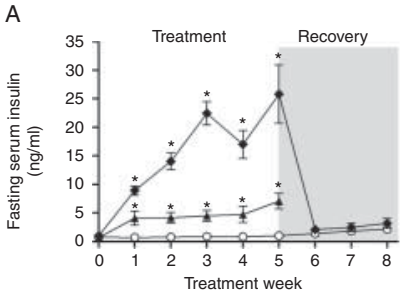

E

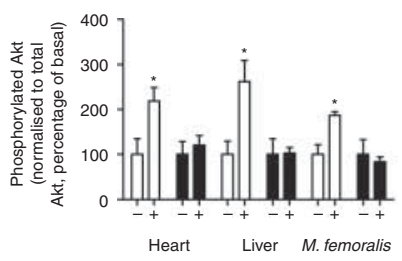

B

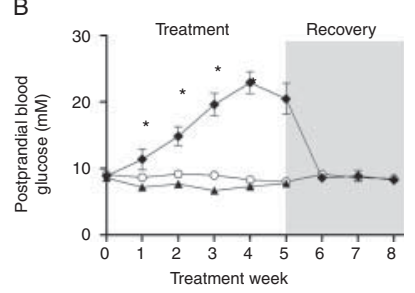

$\mathrm{F}$

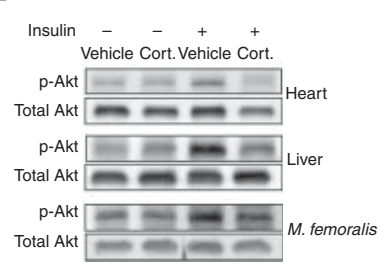

G
C
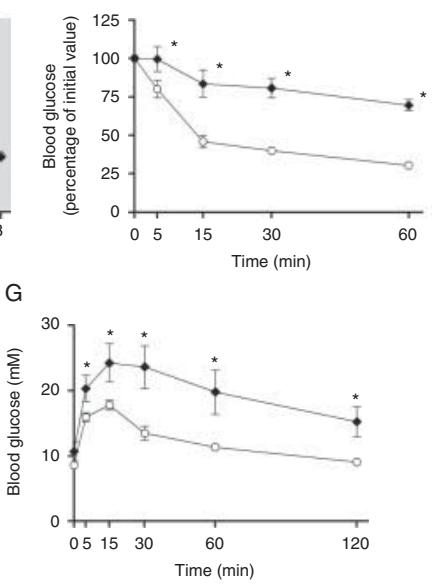

D

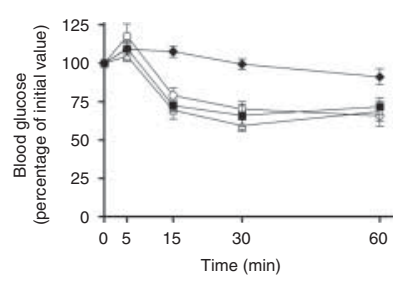

Figure 2

Corticosterone induces reversible glucose intolerance and insulin resistance in mice. Fasting serum insulin (A) and postprandial glycemia (B) are shown during the treatment and recovery (grey background) phases in mice receiving vehicle (white circles), $25 \mu \mathrm{g} / \mathrm{ml}$ corticosterone (black triangles), or $100 \mu \mathrm{g} / \mathrm{ml}$ corticosterone (black diamonds) ( $n=6-36$ during treatment and $n=3-5$ during recovery). Blood glucose levels during IPinsTT (C) and IPGTT (G) are shown after 4 or 5 weeks of treatment, respectively, in mice receiving vehicle (white circles) or $100 \mu \mathrm{g} / \mathrm{ml}$ corticosterone (black diamonds) ( $n=6-11)$. Levels of AKT1/2/3 phosphorylation in different tissues after short IPinsTT ( $E$ and F) in mice receiving vehicle (white bars) or

resistance in all tissues examined. Finally, mice treated with corticosterone $(100 \mu \mathrm{g} / \mathrm{ml})$ were glucose-intolerant compared with vehicle, as seen by their decreased ability to clear glucose after an IPGTT (Fig. 2G). Taken together, these data show that corticosterone, at a dose of $100 \mu \mathrm{g} / \mathrm{ml}$ administrated via the drinking water, induces insulin resistance and glucose intolerance.

\section{Corticosterone effects are reversed upon drug removal}

To test if the metabolic anomalies induced by corticosterone persisted after drug removal, a cohort of mice were treated with $100 \mu \mathrm{g} / \mathrm{ml}$ corticosterone in the drinking water for 5 weeks, as previously described. Thereafter the corticosterone treatment was discontinued and the mice received only vehicle for a recovery period of 3 weeks. Already 1 week after corticosterone withdrawal, fasting serum insulin levels as well as postprandial blood glucose fell to levels similar to those seen in vehicle-treated animals (Fig. 2A and B). In addition, insulin sensitivity, measured via an IPinsTT after 3 weeks without corticosterone, was normalized (Fig. 2D). The accelerated body weight gain seen in corticosterone-treated animals stopped, and at the time of sacrifice the body weight of corticosterone- and vehicle-treated mice was similar, $29.3 \pm 1.7$ and $30.5 \pm 1.2 \mathrm{~g}$, respectively. In concordance,

$100 \mu \mathrm{g} / \mathrm{ml}$ corticosterone (black bars), with PBS $(-)$ or insulin $(+)$ injected i.p. Images in F show representative immunoblots $(n=4-5)$. Blood glucose levels during IPinsTT (D) are shown for mice after 5 weeks of treatment with vehicle (white circles) or $100 \mu \mathrm{g} / \mathrm{ml}$ corticosterone (black diamonds) and for the same mice after 3 weeks of recovery with vehicle (white triangles representing mice on vehicle during the treatment period, black squares representing mice on corticosterone during the treatment period) $(n=3-9)$. Data are shown as mean \pm S.E.M. A * denotes a statistically significant $(P<0.05)$ effect of corticosterone treatment.

fat deposit size in previously corticosterone-treated mice was not different from those seen in vehicle-treated mice 3 weeks after drug removal (data not shown).

\section{Corticosterone exposure in vivo induces pancreatic islet growth and enhances insulin secretion capacity}

Increased islet size has previously been reported in animal models of obesity and insulin resistance (Rafacho et al. 2009). We measured pancreatic insulin content, islet volume, and islet cell proliferation in samples of the pancreatic gland taken from either vehicle-treated or corticosterone-treated $(100 \mu \mathrm{g} / \mathrm{ml})$ mice after 5 weeks of treatment. Pancreata from corticosterone-treated mice contained 2.3-fold more insulin compared with those from the vehicle-treated animals (Fig. 3A). Immunohistological examination of insulin-stained sections revealed that the average islet volume was approximately threefold increased after corticosterone exposure (Fig. 3B). The increased islet volume could be explained by enhanced islet cell proliferation, as the number of BrdU-positive cells per islet volume was increased by a factor of 2.7 (Fig. 3C). We finally analyzed the insulin secretion capacity in islets isolated from vehicle- or corticosterone-treated mice. While there was no difference in the basal insulin release, islets obtained from corticosterone-treated animals

Published by Bioscientifica Ltd 
secreted substantially more insulin in response to $20 \mathrm{mM}$ glucose (Fig. 3D). In conclusion, during corticosterone exposure, islet mass and insulin secretion capacity increase presumably in order to compensate for increased insulin demand due to insulin resistance in the peripheral tissues.

\section{Corticosterone exposure in vivo increases pancreatic islet expression of endoplasmic reticulum chaperones}

Insulin mRNA is translated to preproinsulin which folds in the endoplasmic reticulum (ER) before being packed into secretory vesicles, a process assisted by ER-resident chaperones (Ellgaard \& Helenius 2003). Misfolding of insulin can lead to conditions of ER stress and $\beta$-cell failure (Ortsater \& Sjoholm 2007, Eizirik \& Cnop 2010). We analyzed whether the islet levels of ER chaperones were changed to support the increased secretory demand. Western blot analysis of pancreatic islets from corticosterone-treated mice demonstrated that these islets expressed more of the ER chaperones CALR, PDIA4, and HSP90B1, whereas the levels of HSPA5, CANX, and P4HB were only modestly elevated (Fig. 4A). These observations were supported by an analysis of the mRNA expression levels of the same targets (Fig. 4B). In contrast to the increased chaperone expression, phosphorylation of EIF2K3 and EIF2A was not increased in islets isolated from corticosterone-treated mice (data not shown) and islet preparations from both vehicle- and corticosterone-treated mice contained low levels of DDIT3 (data not shown). From these data, we conclude that the increased demand on insulin secretion from the pancreatic islets, in this model with hyperglycemia and insulin resistance, is followed by an adaptation - not only via an increase in the number of $\beta$-cells and thus islet size - but also via augmentation of islet ER chaperone expression.

\section{Discussion}

This study investigates the effects of exogenously administrated corticosterone on glucose homeostasis in a commonly used mouse strain, the C57BL/6J. We compared vehicle-treated mice with mice exposed to a high dose of corticosterone $(100 \mu \mathrm{g} / \mathrm{ml})$ as well as with a smaller cohort of mice exposed to a lower dose of the steroid $(25 \mu \mathrm{g} / \mathrm{ml})$. As, only the mice treated with the higher dose of corticosterone lost glucose control and displayed postprandial hyperglycemia, only the higher dose was used for further comparisons.
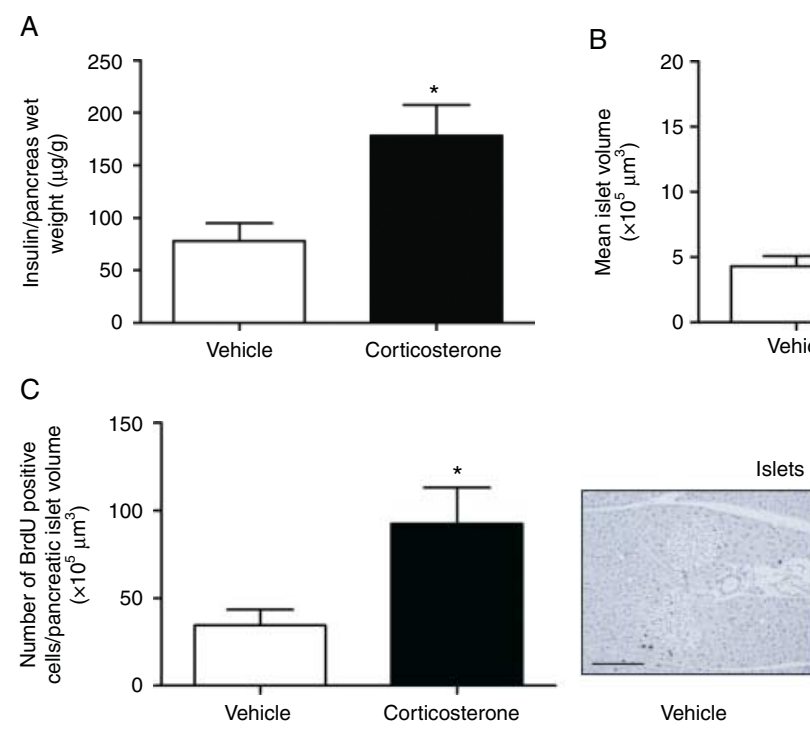

Islets $(\mathrm{BrdU}+)$
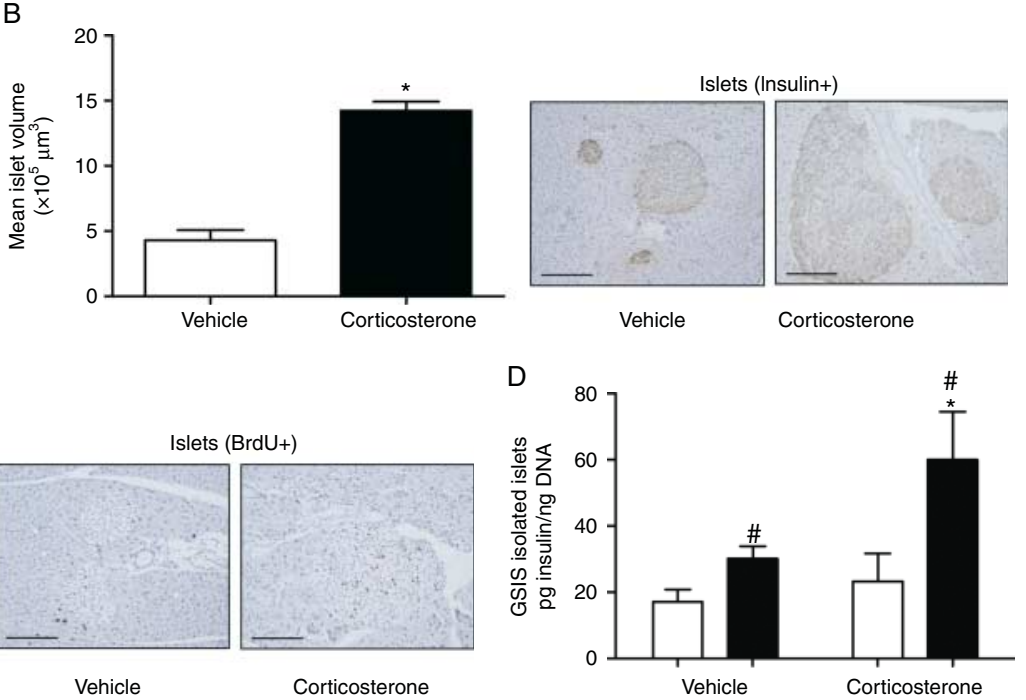

Figure 3

Corticosterone exposure in vivo induces pancreatic islet growth and enhanced insulin secretion in mice. Pancreatic insulin content $(A)$, mean islet volume (B), and number of BrdU-positive cells per pancreatic islet volume $(C)$ are shown after 5 weeks of treatment of mice with vehicle (white bars) or $100 \mu \mathrm{g} / \mathrm{ml}$ corticosterone (black bars). $(n=4-6)$. B and C show representative immunohistochemistry images of islets for volume comparisons and BrdU staining respectively $(20 \times$ magnification, bar represents $150 \mu \mathrm{m}$ ). GSIS in isolated islets (D) with low glucose ( $2 \mathrm{mM}$, white bars) and high glucose ( $20 \mathrm{mM}$, black bars) concentrations are shown after 5 weeks of treatment of mice with vehicle or $100 \mu \mathrm{g} / \mathrm{ml}$ corticosterone. $(n=5-9)$. Data are shown as mean \pm s.E.M. A * denotes a statistically significant $(P<0.05)$ effect of corticosterone treatment and a \# denotes a statistically significant $(P<0.05)$ effect of high glucose. http://joe.endocrinology-journals.org DOI: 10.1530/JOE-13-0189
() 2013 Society for Endocrinology Printed in Great Britain 

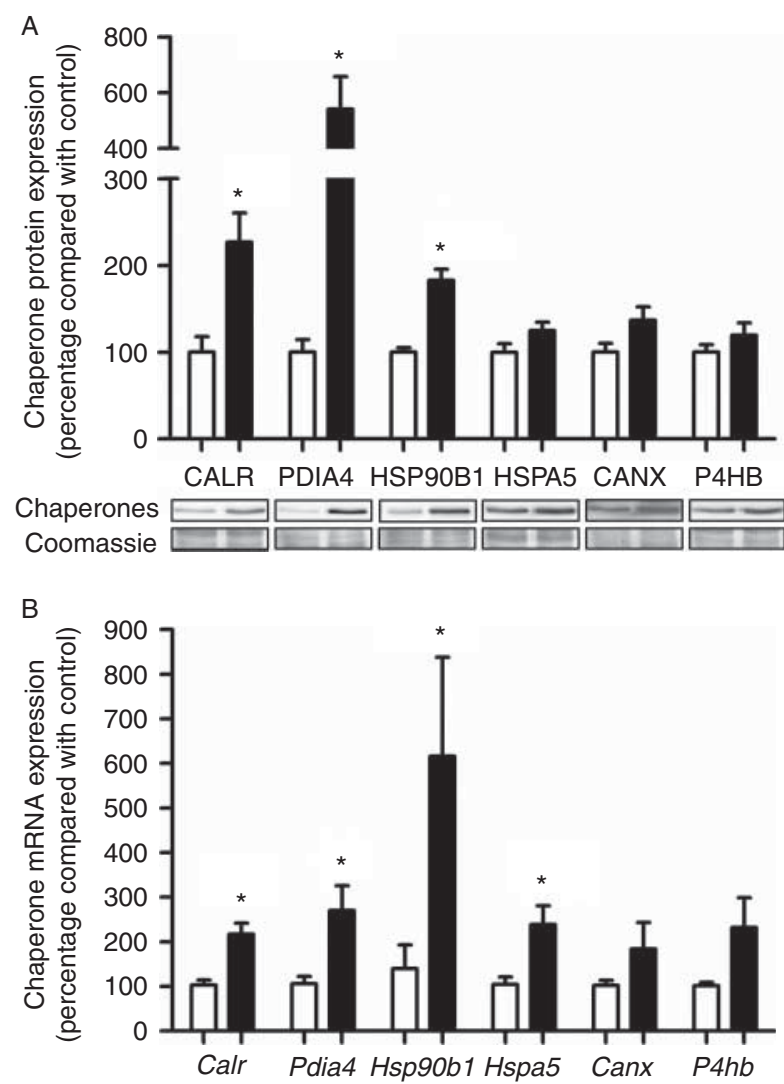

Figure 4

Corticosterone treatment of mice increases pancreatic islet expression of endoplasmic reticulum chaperones. Protein expression (A) $(n=4)$ and mRNA expression (B) $(n=4-5)$ of ER chaperones in isolated islets are shown after 5 weeks of treatment in mice receiving vehicle (white bars) or $100 \mu \mathrm{g} / \mathrm{ml}$ corticosterone (black bars). Images in A show representative immunoblots. Data are shown as mean \pm s.E.M. $A$ * denotes a statistically significant $(P<0.05)$ effect of corticosterone treatment.

Compared with most animal models used to study GC effects, which either rely on adrenalectomy (Christ-Crain et al. 2008) and/or daily injections of GC (Novelli et al. 1999, Rafacho et al. 2008), or surgically inserted GC pellets (Shpilberg et al. 2012), in this study corticosterone was administered via the drinking water. With this approach, animal handling was kept to a minimum and thus inflicted stress (affecting glycemia) was reduced. With the exception of blood sampling once a week, the animals were left undisturbed for 4 weeks after which their insulin sensitivity and glucose handling were investigated via insulin and glucose tolerance tests respectively. In a separate cohort of mice, we also investigated the effects of GC excess on blood pressure. This model with GCs in the drinking water was introduced by Karatsoreos et al. (2010), but in this study we make an in-depth analysis of the metabolic alterations induced by corticosterone.

\section{A model mimicking the metabolic syndrome}

Most importantly, this model of GC excess faithfully recapitulates the phenotype of central obesity seen in patients with Cushing's syndrome as well as in patients with the metabolic syndrome (Pasquali et al. 2006). The increase in food intake and body weight during treatment was expected and has also been reported by Karatsoreos et al. (2010) together with decreased general home-cage activity. Such a weight gain is, however, not seen in rat strains treated with GCs (Rafacho et al. 2008, 2010b, 2011, Shpilberg et al. 2012), but it is a commonly reported adverse effect of GC treatment in humans (McDonough et al. 2008). Thus, by supplying corticosterone via the drinking water, without any other interventions to healthy mice, a net body weight gain is induced. GC treatment is known to induce muscle wasting and a decline in bone density (Schacke et al. 2002). Although we have not performed a careful examination of lean body mass, the increased size of adipose tissue makes it evident that weight gain resulting from fat accumulation surpasses presumed loss of muscle and bone mass.

Not only did GC treatment induce central fat deposit accumulation, it also led to dyslipidemia (in part likewise found by Karatsoreos et al. (2010)), which is also a prominent feature of the human metabolic syndrome. In addition to dyslipidemia, deposition of ectopic fat in the liver and skeletal muscle was evident in GC-treated mice. Ectopic fat accumulation is a condition often referred to as having a substantial negative effect on insulin sensitivity, which also is a key factor of type 2 diabetes and the metabolic syndrome (Hagberg et al. 2012, Tchernof \& Despres 2013). Insulin resistance was consequently demonstrated in this model, evident both when surveying glucose clearance after insulin injection (IPinsTT) and when further studying phosphorylation of AKT1/2/3, a key player in the insulin response required for the insulin-induced translocation of glucose transporter 4 to the plasma membrane (Shepherd 2005). In the heart, liver, and skeletal muscles, the insulin-stimulated phosphorylation of AKT1/2/3 was diminished in mice treated with corticosterone, demonstrating a blunted response to insulin in these tissues. Furthermore, the mice exposed to corticosterone were glucose-intolerant as indicated by the reduced glucose clearance after a glucose challenge (IPGTT) as well as the increase in postprandial glycemia. These increased blood glucose levels were evident in the face of increased fasting serum insulin levels, further corroborating the development of insulin resistance. However, the diabetogenic effects of GC excess

Published by Bioscientifica Ltd 
are transient. When GC treatment was discontinued there was also a remarkably quick - occurring within 1 week - normalization of both serum insulin levels and postprandial hyperglycemia, similar to what has been observed in dexamethasone-treated rats (Rafacho et al. 2010b).

Hypertension is also one of the criteria for the metabolic syndrome in humans (Kassi et al. 2011). Indeed, mice exposed to corticosterone had higher mean arterial pressure compared with vehicle-treated mice. As GCs act by nonspecific binding on the MR in the kidney, sodium retention and potassium excretion increases (Baid \& Nieman 2004). Concomitantly, water retention increases, resulting in augmented plasma volume and thus elevation of blood pressure.

Taken together, these findings - showing body weight gain, increased fat deposits, dyslipidemia, ectopic fat accumulation, glucose intolerance, insulin resistance, and hypertension - present a rodent model mimicking the metabolic syndrome in humans, demonstrating most, if not all, of the criteria for the metabolic syndrome (Kassi et al. 2011). This model for studying the metabolic syndrome or effects of GC excess has the advantage of reduced animal stress due to minimal handling when no surgery or daily injections are needed.

\section{Effects of corticosterone on pancreatic islet adaptation}

Increased islet size has previously been reported in animal models of obesity and insulin resistance (Gepts et al. 1960, Rafacho et al. 2009, Ahren et al. 2010) and this was also evident in this model with GC excess. Both pancreatic insulin content and islet volume were increased in mice exposed to corticosterone. These results suggest that the insulin resistance and increased blood glucose levels in this model give rise to pancreatic islet $\beta$-cell compensation due to the increased demand for insulin. Pancreatic $\beta$-cells have a substantial potential to adapt, which includes increases in insulin production and insulin secretion and in the long run also a higher islet mass due to increased cell proliferation (Sachdeva \& Stoffers 2009). In line with this, this study detected increased BrdU incorporation in islets from mice treated with corticosterone. This suggests that the larger islet size and pancreatic insulin content is due to an increased $\beta$-cell proliferation. Also compensation in terms of increased insulin secretion in islets ex vivo was shown in this study. GSIS was increased in islets from corticosterone-exposed mice, with no difference between vehicle- or corticosterone-treated mice at low glucose. Similar results have previously also been found in islets isolated from rats exposed to dexamethasone (Rafacho et al. 2010a). Related to this, we also found augmented expression of ER chaperones in islets from mice exposed to corticosterone. These results suggest that the ER chaperone expression was increased to meet the elevated secretory demand of insulin from the $\beta$-cells (Eizirik \& Cnop 2010). Enhanced expression of ER chaperones could be an indication of ongoing ER stress. However, as we could not observe increased phosphorylation of either EIF2K3 or EIF2A, and also detected very low and unchanged levels of DDIT3 (which are all markers of ER stress) in the islets obtained from corticosteronetreated mice, it is unlikely that corticosterone has a direct ER stress-inducing effect on islets.

Taken together, we conclude that the increased demand for insulin secretion from the pancreatic islets, in this model with GC-induced hyperglycemia and insulin resistance, is met by an adaptation not only in the number of islet cells and thus islet size but also in increased insulin secretion and in ER chaperone expression. However, while sufficient to maintain fasting normoglycemia, this upregulation of insulin production is inadequate to compensate for the adverse effects of corticosterone on insulin resistance and postprandial hyperglycemia, and the mice display lost glucose control despite the high serum insulin levels.

\section{Conclusion}

In conclusion, this study reveals new features of the mouse model first described by Karatsoreos et al. (2010). These findings show that the model animals in many aspects mimic the metabolic syndrome in humans, demonstrating a net increase in body weight, dyslipidemia, ectopic fat deposition, and hypertension that occur in conjunction with insulin resistance and glucose intolerance. This study also investigates the plasticity of the pancreatic islets in this setting of GC excess, showing initial compensatory effects on islets and ER chaperones. Furthermore, it is clear that the negative metabolic effects of corticosterone are rapidly reversible as both serum insulin levels and blood glucose levels were promptly normalized within 1 week after GC removal. This model of the metabolic syndrome and GC excess has the advantage of not inflicting additional stress to the animals, due to reduced handling and injections and lack of surgery during the study period. This model may preferably be used in efforts to investigate the complex mechanisms behind development of the metabolic syndrome and type 2 diabetes as well as the multifaceted relations between GC excess and disease.

Published by Bioscientifica Ltd. 


\section{Supplementary data}

This is linked to the online version of the paper at http://dx.doi.org/10.1530/ JOE-13-0189.

\section{Declaration of interest}

The authors declare that there is no conflict of interest that could be perceived as prejudicing the impartiality of the research reported.

\section{Funding}

This study was supported by grants from the Diabetes Research and Wellness Foundation, Swedish Diabetes Foundation (Diabetesfonden) and the Tore Nilsson Foundation. H Ortsäter is funded by the Swedish Society for Medical Research. L Fransson is partly funded by KID (Karolinska Institutet, Faculty funds for partial funding of doctoral students).

\section{Author contribution statement}

L Fransson, $\AA$ Sjöholm, and $\mathrm{H}$ Ortsäter conceived and designed the experiments. L Fransson, S Franzén, $\mathrm{V}$ Rosengren, $\mathrm{P}$ Wolbert, and $\mathrm{H}$ Ortsäter performed the experiments. L Fransson, S Franzén, P Wolbert, and $\mathrm{H}$ Ortsäter analyzed the data. L Fransson and $\mathrm{H}$ Ortsäter wrote the paper and S Franzén and $\AA$ Sjöholm edited the paper. All authors have read and approved the final version.

\section{Acknowledgements}

The authors thank the personnel at the research center and the animal facility of Södersjukhuset for animal care. We also thank Dr Annika Mehlem and Dr Annelie Falkevall for advice on ORO-staining, Dr Mohamed Eweida for advice on DNA extraction, and Dr Thomas Nyström for valuable comments on the manuscript.

\section{References}

Ahren J, Ahren B \& Wierup N 2010 Increased $\beta$-cell volume in mice fed a high-fat diet: a dynamic study over 12 months. Islets 2 353-356. (doi:10.4161/isl.2.6.13619)

Anagnostis P, Athyros VG, Tziomalos K, Karagiannis A \& Mikhailidis DP 2009 The pathogenetic role of cortisol in the metabolic syndrome: a hypothesis. Journal of Clinical Endocrinology and Metabolism 94 2692-2701. (doi:10.1210/jc.2009-0370)

Baid S \& Nieman LK 2004 Glucocorticoid excess and hypertension. Current Hypertension Reports 6 493-499. (doi:10.1007/s11906-004-0046-0)

Barel M, Perez OA, Giozzet VA, Rafacho A, Bosqueiro JR \& do Amaral SL 2010 Exercise training prevents hyperinsulinemia, muscular glycogen loss and muscle atrophy induced by dexamethasone treatment. European Journal of Applied Physiology 108 999-1007. (doi:10.1007/ s00421-009-1272-6)

Bock T, Pakkenberg B \& Buschard K 2003 Increased islet volume but unchanged islet number in $o b / o b$ mice. Diabetes 52 1716-1722. (doi:10.2337/diabetes.52.7.1716)

Christ-Crain M, Kola B, Lolli F, Fekete C, Seboek D, Wittmann G, Feltrin D, Igreja SC, Ajodha S, Harvey-White J et al. 2008 AMP-activated protein kinase mediates glucocorticoid-induced metabolic changes: a novel mechanism in Cushing's syndrome. FASEB Journal 22 1672-1683. (doi:10.1096/fj.07-094144)

Duclos M, Marquez Pereira P, Barat P, Gatta B \& Roger P 2005 Increased cortisol bioavailability, abdominal obesity, and the metabolic

http://joe.endocrinology-journals.org DOI: 10.1530/JOE-13-0189
() 2013 Society for Endocrinology Printed in Great Britain syndrome in obese women. Obesity Research 13 1157-1166. (doi:10.1038/oby.2005.137)

Eizirik DL \& Cnop M 2010 ER stress in pancreatic $\beta$ cells: the thin red line between adaptation and failure. Science Signaling 3 pe7. (doi:10.1126/ scisignal.3110pe7)

Ellgaard L \& Helenius A 2003 Quality control in the endoplasmic reticulum. Nature Reviews. Molecular Cell Biology 4 181-191. (doi:10.1038/nrm1052)

Feek CM, Marante DJ \& Edwards CR 1983 The hypothalamic-pituitaryadrenal axis. Clinics in Endocrinology and Metabolism 12 597-618. (doi:10.1016/S0300-595X(83)80057-7)

Gelfand RA, Matthews DE, Bier DM \& Sherwin RS 1984 Role of counterregulatory hormones in the catabolic response to stress. Journal of Clinical Investigation 74 2238-2248. (doi:10.1172/JCI111650)

Gepts W, Christophe J \& Mayer J 1960 Pancreatic islets in mice with the obese-hyperglycemic syndrome: lack of effect of carbutamide. Diabetes 9 63-69. (doi:10.2337/diab.9.1.63)

Grankvist N, Amable L, Honkanen RE, Sjoholm A \& Ortsater H 2012 Serine/threonine protein phosphatase 5 regulates glucose homeostasis in vivo and apoptosis signalling in mouse pancreatic islets and clonal MIN6 cells. Diabetologia 55 2005-2015. (doi:10.1007/s00125012-2541-1)

Gulliford MC, Charlton J \& Latinovic R 2006 Risk of diabetes associated with prescribed glucocorticoids in a large population. Diabetes Care 29 2728-2729. (doi:10.2337/dc06-1499)

Hagberg CE, Falkevall A, Wang X, Larsson E, Huusko J, Nilsson I, van Meeteren LA, Samen E, Lu L, Vanwildemeersch M et al. 2010 Vascular endothelial growth factor B controls endothelial fatty acid uptake. Nature 464 917-921. (doi:10.1038/nature08945)

Hagberg CE, Mehlem A, Falkevall A, Muhl L, Fam BC, Ortsater H, Scotney P, Nyqvist D, Samen E, Lu L et al. 2012 Targeting VEGF-B as a novel treatment for insulin resistance and type 2 diabetes. Nature 490 426-430. (doi:10.1038/nature11464)

Karatsoreos IN, Bhagat SM, Bowles NP, Weil ZM, Pfaff DW \& McEwen BS 2010 Endocrine and physiological changes in response to chronic corticosterone: a potential model of the metabolic syndrome in mouse. Endocrinology 151 2117-2127. (doi:10.1210/en.2009-1436)

Kassi E, Pervanidou P, Kaltsas G \& Chrousos G 2011 Metabolic syndrome: definitions and controversies. BMC Medicine 9 48. (doi:10.1186/17417015-9-48)

Livak KJ \& Schmittgen TD 2001 Analysis of relative gene expression data using real-time quantitative PCR and the $2^{-\Delta \Delta C T}$ method. Methods 25 402-408. (doi:10.1006/meth.2001.1262)

Lowry OH, Rosebrough NJ, Farr AL \& Randall RJ 1951 Protein measurement with the Folin phenol reagent. Journal of Biological Chemistry 193 $265-275$.

Marin P, Darin N, Amemiya T, Andersson B, Jern S \& Bjorntorp P 1992 Cortisol secretion in relation to body fat distribution in obese premenopausal women. Metabolism 41 882-886. (doi:10.1016/00260495(92)90171-6)

McDonough AK, Curtis JR \& Saag KG 2008 The epidemiology of glucocorticoid-associated adverse events. Current Opinion in Rheumatology 20 131-137. (doi:10.1097/BOR.0b013e3282f51031)

Mendizabal Y, Llorens S \& Nava E 2013 Hypertension in metabolic syndrome: vascular pathophysiology. International Journal of Hypertension 2013 230868. (doi:10.1155/2013/230868)

Misra A, Jaiswal A, Shakti D, Wasir J, Vikram NK, Pandey RM, Kondal D \& Bhushan B 2008 Novel phenotypic markers and screening score for the metabolic syndrome in adult Asian Indians. Diabetes Research and Clinical Practice 79 e1-e5. (doi:10.1016/j.diabres.2007. 08.002)

Muhtz C, Zyriax BC, Klahn T, Windler E \& Otte C 2009 Depressive symptoms and metabolic risk: effects of cortisol and gender. Psychoneuroendocrinology 34 1004-1011. (doi:10.1016/j.psyneuen. 2009.01.016) 
Nikolopoulou A \& Kadoglou NP 2012 Obesity and metabolic syndrome as related to cardiovascular disease. Expert Review of Cardiovascular Therapy 10 933-939. (doi:10.1586/erc.12.74)

Novelli M, De Tata V, Bombara M, Lorenzini A, Masini M, Pollera M, Bergamini E \& Masiello P 1999 Insufficient adaptive capability of pancreatic endocrine function in dexamethasone-treated ageing rats. Journal of Endocrinology 162 425-432. (doi:10.1677/joe.0.1620425)

Ortsater H \& Sjoholm A 2007 A busy cell - endoplasmic reticulum stress in the pancreatic $\beta$-cell. Molecular and Cellular Endocrinology 277 1-5. (doi:10.1016/j.mce.2007.06.006)

Pasquali R, Ambrosi B, Armanini D, Cavagnini F, Uberti ED, Del Rio G, de Pergola G, Maccario M, Mantero F, Marugo M et al. 2002 Cortisol and ACTH response to oral dexamethasone in obesity and effects of sex, body fat distribution, and dexamethasone concentrations: a doseresponse study. Journal of Clinical Endocrinology and Metabolism $\mathbf{8 7}$ 166-175. (doi:10.1210/jc.87.1.166)

Pasquali R, Vicennati V, Cacciari M \& Pagotto U 2006 The hypothalamicpituitary-adrenal axis activity in obesity and the metabolic syndrome. Annals of the New York Academy of Sciences 1083 111-128. (doi:10.1196/ annals.1367.009)

Patterson ZR, Khazall R, Mackay H, Anisman H \& Abizaid A 2013 Central ghrelin signaling mediates the metabolic response of C57BL/6 male mice to chronic social defeat stress. Endocrinology 154 1080-1091. (doi:10.1210/en.2012-1834)

Quan ZY \& Walser M 1992 Effects of corticosterone administration on nitrogen excretion and nitrogen balance in adrenalectomized rats. American Journal of Clinical Nutrition 55 695-700.

Rafacho A, Giozzet VA, Boschero AC \& Bosqueiro JR 2008 Functional alterations in endocrine pancreas of rats with different degrees of dexamethasone-induced insulin resistance. Pancreas 36 284-293. (doi:10.1097/MPA.0b013e31815ba826)

Rafacho A, Cestari TM, Taboga SR, Boschero AC \& Bosqueiro JR 2009 High doses of dexamethasone induce increased $\beta$-cell proliferation in pancreatic rat islets. American Journal of Physiology. Endocrinology and Metabolism 296 E681-E689. (doi:10.1152/ajpendo.90931.2008)

Rafacho A, Marroqui L, Taboga SR, Abrantes JL, Silveira LR, Boschero AC, Carneiro EM, Bosqueiro JR, Nadal A \& Quesada I 2010a Glucocorticoids in vivo induce both insulin hypersecretion and enhanced glucose sensitivity of stimulus-secretion coupling in isolated rat islets. Endocrinology 151 85-95. (doi:10.1210/en.2009-0704)

Rafacho A, Quallio S, Ribeiro DL, Taboga SR, Paula FM, Boschero AC \& Bosqueiro JR $2010 b$ The adaptive compensations in endocrine pancreas from glucocorticoid-treated rats are reversible after the interruption of treatment. Acta Physiologica 200 223-235. (doi:10.1111/j.1748-1716. 2010.02146.x)

Rafacho A, Abrantes JL, Ribeiro DL, Paula FM, Pinto ME, Boschero AC \& Bosqueiro JR 2011 Morphofunctional alterations in endocrine pancreas of short- and long-term dexamethasone-treated rats. Hormone and Metabolic Research 43 275-281. (doi:10.1055/s-0030-1269896)

Raul Ariza-Andraca C, Barile-Fabris LA, Frati-Munari AC \& BaltazarMontufar P 1998 Risk factors for steroid diabetes in rheumatic patients. Archives of Medical Research 29 259-262.
Reynolds RM, Walker BR, Syddall HE, Whorwood CB, Wood PJ \& Phillips DI 2001 Elevated plasma cortisol in glucose-intolerant men: differences in responses to glucose and habituation to venepuncture. Journal of Clinical Endocrinology and Metabolism 86 1149-1153. (doi:10.1210/jc.86.3.1149)

Rosmond R, Dallman MF \& Bjorntorp P 1998 Stress-related cortisol secretion in men: relationships with abdominal obesity and endocrine, metabolic and hemodynamic abnormalities. Journal of Clinical Endocrinology and Metabolism 83 1853-1859. (doi:10.1210/ jc.83.6.1853)

Sachdeva MM \& Stoffers DA 2009 Minireview: meeting the demand for insulin: molecular mechanisms of adaptive postnatal $\beta$-cell mass expansion. Molecular Endocrinology 23 747-758. (doi:10.1210/ me.2008-0400)

Sargsyan E, Ortsater H, Thorn K \& Bergsten P 2008 Diazoxide-induced $\beta$-cell rest reduces endoplasmic reticulum stress in lipotoxic $\beta$-cells. Journal of Endocrinology 199 41-50. (doi:10.1677/JOE-08-0251)

Schacke H, Docke WD \& Asadullah K 2002 Mechanisms involved in the side effects of glucocorticoids. Pharmacology \& Therapeutics 96 23-43. (doi:10.1016/S0163-7258(02)00297-8)

Sen Y, Aygun D, Yilmaz E \& Ayar A 2008 Children and adolescents with obesity and the metabolic syndrome have high circulating cortisol levels. Neuroendocrinology Letters 29 141-145.

Shepherd PR 2005 Mechanisms regulating phosphoinositide 3-kinase signalling in insulin-sensitive tissues. Acta Physiologica Scandinavica 183 3-12. (doi:10.1111/j.1365-201X.2004.01382.x)

Shpilberg Y, Beaudry JL, D'Souza A, Campbell JE, Peckett A \& Riddell MC 2012 A rodent model of rapid-onset diabetes induced by glucocorticoids and high-fat feeding. Disease Models \& Mechanisms 5 671-680. (doi:10.1242/dmm.008912)

Tchernof A \& Despres JP 2013 Pathophysiology of human visceral obesity: an update. Physiological Reviews 93 359-404. (doi:10.1152/physrev. 00033.2011)

Vegiopoulos A \& Herzig S 2007 Glucocorticoids, metabolism and metabolic diseases. Molecular and Cellular Endocrinology 275 43-61. (doi:10.1016/ j.mce.2007.05.015)

Vogelzangs N, Suthers K, Ferrucci L, Simonsick EM, Ble A, Schrager M, Bandinelli S, Lauretani F, Giannelli SV \& Penninx BW 2007 Hypercortisolemic depression is associated with the metabolic syndrome in late-life. Psychoneuroendocrinology 32 151-159. (doi:10.1016/ j.psyneuen.2006.11.009)

Wajchenberg BL, Prestes Cesar F, Okada H, Torres de Toledo e Souza I, Lerario AC, Borghi VC, Malerbi DA, Giurna Filho A, Liberman B \& Gianella D 1984 Glucocorticoids, glucose metabolism and hypothalamic-pituitary-adrenal axis. Advances in Experimental Medicine and Biology $17125-44$.

Weigensberg MJ, Toledo-Corral CM \& Goran MI 2008 Association between the metabolic syndrome and serum cortisol in overweight Latino youth. Journal of Clinical Endocrinology and Metabolism 93 1372-1378. (doi:10.1210/jc.2007-2309)

Received in final form 30 August 2013

Accepted 17 September 2013

Accepted Preprint published online 17 September 2013 http://joe.endocrinology-journals.org DOI: 10.1530/JOE-13-0189
() 2013 Society for Endocrinology Printed in Great Britain 